\title{
Sweets and sugar-sweetened soft drink intake in childhood in relation to adult BMl and overweight. The Cardiovascular Risk in Young Finns Study
}

\author{
Katja Nissinen ${ }^{1, *}$, Vera Mikkilä2 ${ }^{2}$ Satu Männistö ${ }^{3}$, Marjaana Lahti-Koski $^{1,4}$, \\ Leena Räsänen ${ }^{2}$, Jorma Viikari ${ }^{5}$ and Olli T Raitakari ${ }^{6}$ \\ ${ }^{1}$ Nutrition Unit, National Institute for Health and Welfare, PO Box 30, FIN-00271 Helsinki, Finland: \\ ${ }^{2}$ Department of Applied Chemistry and Microbiology, Division of Nutrition, PO Box 66, FIN-00014 University \\ of Helsinki, Helsinki, Finland: ${ }^{3}$ Chronic Disease Prevention and Epidemiology Unit, National Institute for Health \\ and Welfare, PO Box 30, FIN-00271 Helsinki, Finland: ${ }^{4}$ Finnish Heart Association, PO Box 50, FIN-0062 1 \\ Helsinki, Finland: ${ }^{5}$ Department of Medicine, University of Turku and Turku University Central Hospital, \\ PO Box 52, FIN-20521 Turku, Finland: 'Department of Clinical Physiology, Turku University Central Hospital, \\ PO Box 52, FIN-20521 Turku, Finland
}

Submitted 24 November 2007: Accepted 23 March 2009: First published online 28 May 2009

\begin{abstract}
Objective: To investigate the associations of BMI and overweight in adulthood with consumption of sweets and sugar-sweetened soft drinks in childhood and with the change in consumption between childhood and adulthood.

Design: Longitudinal 21-year follow-up study of Finnish children and adolescents from childhood to adulthood.

Setting: The Cardiovascular Risk in Young Finns Study, comprising participants from both eastern and western Finland.

Subjects: Boys ( $n$ 967) and girls ( $n$ 1172) aged 3-18 years at baseline in 1980.

Results: The increase in consumption of sugar-sweetened soft drinks from childhood to adulthood was directly associated with BMI in adulthood in women ( $b=0 \cdot 45, P=0 \cdot 0001$ ) but not in men. In women, BMI increased by $0 \cdot 45 \mathrm{~kg} / \mathrm{m}^{2}$ for every 10-unit increase per month. Consumption of sweets and sugar-sweetened soft drinks in childhood and adolescence was not associated with BMI in adulthood. The change in consumption of sweets was not associated with BMI in adulthood. The increase in the consumption of sugar-sweetened soft drinks from childhood to adulthood was associated with being overweight (OR $=1 \cdot 90,95 \%$ CI $1 \cdot 38,2 \cdot 61$ ) in women, but not in men. No association was found between overweight (BMI $\geq 25 \mathrm{~kg} / \mathrm{m}^{2}$ ) in adulthood and consumption of sweets in childhood or the change in consumption from childhood to adulthood.

Conclusions: We conclude that direct associations exist between adulthood overweight and BMI and an increase in consumption of sugar-sweetened soft drinks in women. Thus sugar-sweetened soft drinks consumption may be important when considering weight management in women.
\end{abstract}

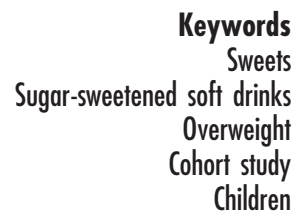

The prevalence of overweight and obesity has increased substantially in Finland, particularly among children, adolescents and young adults ${ }^{(1)}$. According to the International Obesity Taskforce ${ }^{(2)}$, the cause of the obesity epidemic is considered twofold: the abundance of energy-dense foods and drinks, leading to passive over-consumption of energy, and an environment with limited opportunities for physical activity, leading to an almost universal sedentary state.

Worldwide, the consumption of caloric sweeteners has increased markedly over the past years with beverages being a major contributor ${ }^{(3)}$. In Finland, domestic sales of sweets have risen by $40 \%$ over two decades ${ }^{(4)}$ and the consumption of soft drinks has doubled from 1980 to $2004^{(5)}$. Although the biggest increase has occurred in the consumption of artificially sweetened soft drinks, the proportion of sugarsweetened soft drinks is still $70 \%$ of all soft drinks ${ }^{(6)}$.

Research regarding consumption of sweets and obesity is rare, and the results are inconsistent. A longitudinal study of children in the $\mathrm{USA}^{(7)}$ showed no relationship to weight gain, and in a cross-sectional study of thirty-four (primarily European) countries ${ }^{(8)}$ the frequency of sweets consumption was lower in overweight adolescents. The consumption of sugar-sweetened soft drinks has been in focus for its potential role as a risk factor for overweight 
and obesity ${ }^{(7,9-13)}$. Longitudinal US studies have reported consumption to be directly associated with obesity in children and adult females ${ }^{(10,12,13)}$. In contrast, a Norwegian study with a substantially longer follow-up from adolescence to adulthood (20 years) reported no association between body weight and consumption of sugar-sweetened soft drinks ${ }^{(11)}$.

Because body weight is a result of health behaviour over time, the effects of sweets and sugar-sweetened soft drinks during a long period are of interest. To our knowledge, only one study ${ }^{(11)}$ has investigated the association between childhood sugar-sweetened soft drink consumption and adult overweight, and no studies have investigated the association between childhood consumption of sweets and adult overweight. Thus the aims of the present study were to investigate: (i) the associations of BMI and overweight in adulthood with the consumption of sweets and sugarsweetened soft drinks in childhood; and (ii) the associations of BMI and overweight in adulthood with the change in consumption of sweets and sugar-sweetened soft drinks between childhood and adulthood.

\section{Experimental methods}

\section{Study design}

The Cardiovascular Risk in Young Finns Study is a large, longitudinal, multi-centre study on CVD risk factors and their determinants among children, adolescents and young adults in Finland. The protocol has included analogous data collection methods over a 21-year period, including physical and biochemical measurements as well as dietary interviews at the study centres, and self-administered questionnaires on diet, smoking, physical activity and other lifestyle factors, and on participants' and their families' sociodemographic status. Anthropometric measurements have included the repeated measurement of participants' weight and height. A written informed consent was obtained from all participants and the ethical committees of the participating centres approved the study protocol of the project. Details of the methods have been described previously elsewhere ${ }^{(14,15)}$.

\section{Study population}

The baseline study was carried out in 1980, when randomly selected participants from both eastern and western Finland were 3, 6, 9, 12, 15 and 18 years of age (total of 3596 subjects, $83 \%$ of those invited), and the same participants have been followed since. After 21 years, those who had participated in 1980 and still had a permanent address in Finland ( $n$ 3456) were invited to the follow-up field study; 2280 participants ( $66 \%$ of those participating at baseline) participated. Lack of time (33\%), absence from the place of residence at the time of the examination (13\%) and unwillingness to participate (13\%) were cited as the main reasons for non-participation ${ }^{(16)}$. Dropouts were more often men and younger than those who stayed in the study. Comparing dropouts and follow-up participants using age-adjusted analyses separately among men and women, there were no statistically significant differences in baseline BMI, parents' education, cardiovascular risk factors including serum lipids and blood pressure ${ }^{(17)}$ or in the baseline frequency of consumption of sweets and sugarsweetened soft drinks (data not shown). After excluding participants with incomplete data on weight, height or consumption of sweets and sugar-sweetened soft drinks, 2139 participants were included in the current study.

\section{Assessment of consumption of sweets and sugar-sweetened soft drinks}

Both at baseline in 1980 and at the follow-up in 2001, the participants were given a self-administered questionnaire on habitual dietary choices when visiting the research centre and asked to return it by mail when completed. In 1980, a parent or guardian filled in the form for children belonging to the two youngest age cohorts ( 3 and 6 years). Although the questionnaires were not totally identical in 1980 and in 2001 (consisting of nineteen and twenty-one questions, respectively) they both included identical questions on the consumption of sweets and sugar-sweetened soft drinks, with six frequency categories from 'daily' to 'never'. On the basis of these answers, we calculated a variable representing the number of units consumed per month separately for sweets and sugar-sweetened soft drinks. For example, the frequency category 'daily' was transformed to 30 units per month, 'once a week' to 4 units per month and the frequency category 'never' to 0 units per month. Furthermore, we divided the participants into three age- and sex-specific groups based on the change in the number of units consumed and describing the change in their position relative to other participants: 'increase' indicating moving upwards in the groups, 'decrease' indicating moving downwards and 'no change' indicating remaining in the same group after 21 years. The 'no change' group was furthermore divided into 'stable low' and 'stable high' groups. Stable low indicates being in the lowest and the middle group and stable high being in the highest group.

In addition, we combined the two highest ('daily' or 'nearly' daily), two middle ('2-3 times a week' and 'once a week') and the two lowest ('rarely or never' and '2-3 times a month') frequency categories. The validity of the questionnaire has been reported elsewhere ${ }^{(18)}$; significant correlation was found between information obtained by a $48 \mathrm{~h}$ dietary recall and by the questionnaire measuring longer-term food choices.

\section{Assessment of weight status}

Weight (to the nearest $0 \cdot 1 \mathrm{~kg}$ ) and height (to the nearest $0 \cdot 1 \mathrm{~cm}$ ) were measured by a trained nurse. BMI was calculated as the participant's weight in kilograms divided by the square of their height in metres $\left(\mathrm{kg} / \mathrm{m}^{2}\right)$. For participants 
aged 18 years and older, overweight and obesity were defined as BMI $\geq 25 \mathrm{~kg} / \mathrm{m}^{2}$ and $\mathrm{BMI} \geq 30 \mathrm{~kg} / \mathrm{m}^{2}$, respectively ${ }^{(19)}$. The sex- and age-defined BMI cut-off points suggested by Cole $e t a l{ }^{(20)}$ were used for children and adolescents aged $3-15$ years.

\section{Assessment of other variables}

Information on education, physical activity and smoking was assessed with self-administered questionnaires in 1980 and 2001. We used the length of parents' education as an indicator of the socio-economic status of the family in childhood. Information on the parent with more years of education was included in the analyses. In adulthood, we assessed the participant's own years of education. Level of education, based on the schooling system in Finland, was defined by using 9 and 12 years of schooling as cut-off points. Physical activity in adulthood was categorized using the frequency of rigorous exercise (minimum duration of $30 \mathrm{~min}$ ) into three categories: less than weekly, weekly and more than weekly. According to smoking status in adulthood, participants were classified into three groups: regular smokers, ex-smokers and never smokers.

\section{Statistical analyses}

We conducted a multivariable, linear regression analysis to examine the independent associations between consumption of sweets and sugar-sweetened soft drinks and adulthood BMI. Adult BMI (in 2001) was inserted into the models as the outcome, and separate models with the consumption of sweets and sugar-sweetened soft drinks (as units per month) or the change in consumption as the predictor variable were conducted. The first models were adjusted for age and overweight status in childhood. Model 2 was additionally controlled for either parental education (childhood predictors) or participant's own education (change in consumption as the predictor), and model 3 for smoking and physical activity in adulthood. Associations with a $P$ value of less than 0.05 were considered statistically significant.

We also carried out logistic regression analyses to study the risk of being overweight in adulthood according to the frequency of sweets and sugar-sweetened soft drinks consumption in childhood or the change in this consumption from childhood to adulthood. Adjustments were carried out as in linear regression analyses. Odds ratios with a $95 \%$ confidence interval excluding 1 were defined as statistically significant. All statistical analyses were carried out using the SAS for Windows statistical software package versions $8 \cdot 2$ and $9 \cdot 1$ (SAS Institute Inc., Cary, NC, USA).

\section{Results}

\section{BMI, overweight and obesity}

In childhood and adolescence (in 1980), $7 \cdot 8 \%$ of both boys and girls were overweight (Table 1 ). In the youngest
Table 1 Characteristics of study participants at childhood (in 1980) and adulthood (in 2001): Cardiovascular Risk in Young Finns Study

\begin{tabular}{|c|c|c|c|}
\hline & & Males & Females \\
\hline & Participants, $n$ & 967 & 1172 \\
\hline \multirow[t]{14}{*}{1980} & $\begin{array}{l}\text { Age (years), mean (range 3-18) } \\
\text { Overweight }(\%)^{\star}\end{array}$ & $10 \cdot 7$ & $10 \cdot 7$ \\
\hline & $\begin{array}{l}\text { All } \\
\text { By age group in } 1980\end{array}$ & $7 \cdot 8$ & $7 \cdot 8$ \\
\hline & $3-6$ years & $5 \cdot 2$ & $8 \cdot 8$ \\
\hline & $9-12$ years & $9 \cdot 0$ & $9 \cdot 9$ \\
\hline & $15-18$ years & $8 \cdot 7$ & $4 \cdot 6$ \\
\hline & Obese $(\%)^{\star}$ & & \\
\hline & $\begin{array}{l}\text { All } \\
\text { By age group in } 1980\end{array}$ & 1.5 & 0.9 \\
\hline & $3-6$ years & $1 \cdot 7$ & $1 \cdot 6$ \\
\hline & $9-12$ years & 0.9 & $1 \cdot 0$ \\
\hline & $15-18$ years & $1 \cdot 8$ & $0 \cdot 3$ \\
\hline & Parental education (\%) & & \\
\hline & $\leq 9$ years & $44 \cdot 2$ & $47 \cdot 4$ \\
\hline & 10-12 years & $29 \cdot 3$ & $28 \cdot 2$ \\
\hline & $>12$ years & $26 \cdot 5$ & $24 \cdot 4$ \\
\hline \multirow[t]{25}{*}{2001} & Age (years), mean (range 24-39) & $31 \cdot 7$ & $31 \cdot 7$ \\
\hline & BMI $\left(\mathrm{kg} / \mathrm{m}^{2}\right)$, mean & $25 \cdot 7$ & $24 \cdot 5$ \\
\hline & Overweight, $\mathrm{BMI} \geq 25 \mathrm{~kg} / \mathrm{m}^{2}(\%)$ & & \\
\hline & $\begin{array}{l}\text { All } \\
\text { By age group in } 2001\end{array}$ & $52 \cdot 0$ & $36 \cdot 2$ \\
\hline & $24-27$ years & $39 \cdot 7$ & 31.5 \\
\hline & 30-33 years & $55 \cdot 9$ & $38 \cdot 7$ \\
\hline & $36-39$ years & $58 \cdot 8$ & $37 \cdot 8$ \\
\hline & Obese, $\mathrm{BMI} \geq 30 \mathrm{~kg} / \mathrm{m}^{2}(\%)$ & & \\
\hline & All & $13 \cdot 3$ & $11 \cdot 0$ \\
\hline & By age group in 2001 & & \\
\hline & 24-27 years & $7 \cdot 4$ & $8 \cdot 4$ \\
\hline & $30-33$ years & $12 \cdot 8$ & $13 \cdot 7$ \\
\hline & 36-39 years & $19 \cdot 1$ & $10 \cdot 4$ \\
\hline & Education (\%) & & \\
\hline & $\leq 9$ years & $4 \cdot 6$ & $3 \cdot 0$ \\
\hline & 10-12 years & $33 \cdot 3$ & $20 \cdot 8$ \\
\hline & $>12$ years & $62 \cdot 0$ & $76 \cdot 3$ \\
\hline & Physical activity ( $\geq 30 \mathrm{~min})(\%)$ & & \\
\hline & Less than weekly & $8 \cdot 3$ & $7 \cdot 9$ \\
\hline & Weekly & $49 \cdot 5$ & $43 \cdot 7$ \\
\hline & More than weekly & $42 \cdot 2$ & $48 \cdot 4$ \\
\hline & Smoking (\%) & & \\
\hline & Regular smoker & $43 \cdot 4$ & $28 \cdot 5$ \\
\hline & Ex-smoker & $17 \cdot 2$ & $18 \cdot 2$ \\
\hline & Never smoker & $39 \cdot 4$ & $53 \cdot 3$ \\
\hline
\end{tabular}

${ }^{*}$ Defined by Cole et al. ${ }^{(20)}$.

age group (3-6 years), the prevalence of overweight was higher in girls than in boys $(8.8 \% v .5 \cdot 2 \%)$, whereas in the oldest group (15-18 years), the prevalence of overweight was higher in boys than in girls $(8 \cdot 7 \% v .4 \cdot 6 \%)$. In adulthood (in 2001, aged 24-39), $52.0 \%$ of men and $36 \cdot 2 \%$ of women were overweight $\left(\mathrm{BMI} \geq 25 \mathrm{~kg} / \mathrm{m}^{2}\right)$, and $13.3 \%$ of men and $11.0 \%$ of women were obese $\left(\mathrm{BMI} \geq 30 \mathrm{~kg} / \mathrm{m}^{2}\right)$. The mean BMI in adulthood was $25.7 \mathrm{~kg} / \mathrm{m}^{2}$ for men and $24.5 \mathrm{~kg} / \mathrm{m}^{2}$ for women. The prevalence of overweight by age varied in men from $39 \cdot 7 \%$ in the youngest age group (24-27 years) to $58.8 \%$ in the oldest age group (36-39 years) and in women from $31.5 \%$ in the youngest group (24-27 years) to $38.7 \%$ in the middle age group ( $30-33$ years), and that of obesity in men from $7 \cdot 4 \%$ (24-27 years) to $19 \cdot 1 \%$ (36-39 years) 
and in women from $8 \cdot 4 \%(24-27$ years) to $13 \cdot 7 \%$ (30-33 years).

\section{Consumption frequency of sweets and sugar- sweetened soft drinks}

The frequency of consumption of sweets and sugarsweetened soft drinks between childhood and adulthood is presented in Table 2 . In childhood, a bigger proportion of the two oldest groups consumed sweets daily or nearly every day than of the youngest group. However, almost $90 \%$ of the youngest group consumed sweets at least once a week. In adulthood, women were more often daily or nearly every day consumers of sweets than men. The trend was similar in all groups in adulthood. In childhood, more than $70 \%$ of boys from all age groups and of 9- to 12-year-old girls consumed sugar-sweetened soft drinks at least once a week. In adulthood, $45 \%$ of women and $71 \%$ of men consumed sugar-sweetened soft drinks at least once a week.

\section{Sweets and sugar-sweetened soft drinks and BMI}

The association between the consumption of sweets and sugar-sweetened soft drinks in childhood and adulthood BMI is shown in Table 3. The consumption of sweets or sugar-sweetened soft drinks in childhood was not significantly associated with BMI in adulthood after adjusting for age and overweight status in childhood and education, smoking and physical activity in adulthood. The change in consumption of sugar-sweetened soft drinks between childhood and adulthood was significantly associated with BMI in adulthood in women but not in men. After adjusting for age and overweight status in childhood (in 1980) and for education, smoking and physical activity in adulthood (in 2001), the estimated BMI was $0 \cdot 45 \mathrm{~kg} / \mathrm{m}^{2}(b=0 \cdot 45, P=0 \cdot 0001)$ higher for every 10-unit increase in the consumption of sugarsweetened soft drinks per month in women. The change in consumption of sweets was not associated with adulthood BMI in either men or women.

\section{Sweets and sugar-sweetened soft drinks and overweight}

No statistically significant association was found between overweight (BMI $\geq 25 \mathrm{~kg} / \mathrm{m}^{2}$ ) in adulthood and the frequency of consumption of sweets and sugar-sweetened soft drinks in childhood using logistic regression analysis (data not shown). The change in the consumption of sweets and sugar-sweetened soft drinks was also assessed

Table 2 Distribution (\%) of frequency of consumption of sweets and sugar-sweetened soft drinks in study participants by gender and by age group: Cardiovascular Risk in Young Finns Study

\begin{tabular}{|c|c|c|c|c|c|c|c|c|}
\hline & \multirow{2}{*}{\multicolumn{2}{|c|}{ All }} & \multicolumn{6}{|c|}{ Age group in 1980} \\
\hline & & & \multicolumn{2}{|c|}{$3-6$ years } & \multicolumn{2}{|c|}{$9-12$ years } & \multicolumn{2}{|c|}{$15-18$ years } \\
\hline & Males & Females & Males & Females & Males & Females & Males & Females \\
\hline Participants, $n$ & 967 & 1172 & 297 & 368 & 345 & 416 & 335 & 394 \\
\hline \multicolumn{9}{|l|}{ Sweets } \\
\hline Rarely or never & 1980 & 4 & 6 & 5 & 3 & 3 & 6 & 4 \\
\hline $2-3$ times a month & 9 & 7 & 5 & 7 & 7 & 6 & 15 & 7 \\
\hline Once a week & 34 & 34 & 52 & 53 & 34 & 34 & 19 & 17 \\
\hline $2-3$ times a week & 30 & 32 & 26 & 26 & 33 & 34 & 29 & 34 \\
\hline Nearly every day & 18 & 18 & 9 & 7 & 18 & 19 & 25 & 29 \\
\hline Daily & 4 & 5 & 2 & 2 & 5 & 4 & 6 & 9 \\
\hline \multicolumn{9}{|l|}{2001} \\
\hline Rarely or never & 5 & 5 & 4 & 4 & 6 & 6 & 6 & 5 \\
\hline $2-3$ times a month & 20 & 12 & 21 & 12 & 19 & 14 & 18 & 11 \\
\hline Once a week & 27 & 29 & 27 & 30 & 25 & 26 & 29 & 30 \\
\hline 2-3 times a week & 31 & 33 & 30 & 31 & 30 & 33 & 32 & 34 \\
\hline Nearly every day & 14 & 18 & 14 & 21 & 17 & 18 & 13 & 16 \\
\hline Daily & 3 & 3 & 4 & 3 & 3 & 3 & 2 & 4 \\
\hline \multicolumn{9}{|l|}{ Soft drinks } \\
\hline \multicolumn{9}{|l|}{1980} \\
\hline Rarely or never & 9 & 11 & 12 & 12 & 7 & 8 & 8 & 14 \\
\hline 2-3 times a month & 13 & 18 & 14 & 19 & 12 & 15 & 12 & 21 \\
\hline Once a week & 25 & 26 & 27 & 22 & 28 & 32 & 21 & 23 \\
\hline $2-3$ times a week & 23 & 20 & 18 & 17 & 21 & 19 & 29 & 23 \\
\hline Nearly every day & 19 & 17 & 20 & 19 & 18 & 20 & 20 & 13 \\
\hline Daily & 11 & 8 & 9 & 11 & 14 & 6 & 10 & 6 \\
\hline \multicolumn{9}{|l|}{2001} \\
\hline Rarely or never & 9 & 24 & 4 & 21 & 7 & 22 & 15 & 31 \\
\hline 2-3 times a month & 20 & 31 & 19 & 29 & 20 & 32 & 21 & 32 \\
\hline Once a week & 26 & 20 & 25 & 19 & 25 & 21 & 27 & 20 \\
\hline $2-3$ times a week & 27 & 16 & 31 & 17 & 28 & 16 & 22 & 13 \\
\hline Nearly every day & 13 & 6 & 14 & 7 & 14 & 7 & 12 & 3 \\
\hline Daily & 5 & 3 & 7 & 7 & 6 & 2 & 3 & 1 \\
\hline
\end{tabular}


Table 3 Predicted difference in adult BMI per 10-unit consumption difference for sweets and sugar-sweetened soft drinks and in change in consumption frequency: Cardiovascular Risk in Young Finns Study

\begin{tabular}{|c|c|c|c|c|c|c|c|c|c|c|c|c|}
\hline & \multicolumn{6}{|c|}{ Childhood consumption } & \multicolumn{6}{|c|}{ Change in consumption } \\
\hline & \multicolumn{3}{|c|}{ Males } & \multicolumn{3}{|c|}{ Females } & \multicolumn{3}{|c|}{ Males } & \multicolumn{3}{|c|}{ Females } \\
\hline & $b$ & SE & $P$ & $b$ & $\mathrm{SE}$ & $P$ & $b$ & SE & $P$ & $b$ & $\mathrm{SE}$ & $P$ \\
\hline \multicolumn{13}{|l|}{ Sweets } \\
\hline Model 1 & -0.02 & $0 \cdot 15$ & 0.91 & -0.04 & $0 \cdot 15$ & 0.77 & -0.16 & $0 \cdot 12$ & $0 \cdot 20$ & -0.19 & 0.12 & $0 \cdot 11$ \\
\hline Model 2 & $<0.01$ & $0 \cdot 14$ & 0.98 & 0.03 & $0 \cdot 14$ & 0.85 & $-0 \cdot 11$ & $0 \cdot 11$ & 0.31 & $-0 \cdot 13$ & $0 \cdot 11$ & 0.23 \\
\hline Model 3 & - & - & - & - & - & - & $-0 \cdot 13$ & $0 \cdot 11$ & $0 \cdot 25$ & $-0 \cdot 12$ & $0 \cdot 11$ & $0 \cdot 27$ \\
\hline \multicolumn{13}{|l|}{ Soft drinks } \\
\hline Model 1 & 0.03 & $0 \cdot 14$ & 0.83 & $-0 \cdot 17$ & $0 \cdot 15$ & 0.26 & -0.02 & $0 \cdot 11$ & 0.85 & 0.46 & 0.12 & $<0.001$ \\
\hline Model 2 & 0.01 & 0.01 & 0.51 & $-0 \cdot 16$ & $0 \cdot 14$ & 0.24 & -0.01 & $0 \cdot 10$ & 0.93 & 0.44 & $0 \cdot 11$ & $<0.001$ \\
\hline Model 3 & - & - & - & - & - & - & -0.04 & 0.11 & 0.71 & 0.45 & $0 \cdot 12$ & $<0.001$ \\
\hline
\end{tabular}

Model 1: adjusted for age in childhood.

Model 2 (childhood consumption): adjusted for age, overweight status and parental education in childhood.

Model 2 (change in consumption): adjusted for age and overweight status in childhood and education in adulthood.

Model 3 (change in consumption): adjusted for age and overweight status in childhood and education, smoking and physical activity in adulthood.

Table 4 Association of overweight $\left(B M I \geq 25 \mathrm{~kg} / \mathrm{m}^{2}\right)$ in adulthood with change in the frequency of consumption (from childhood to adulthood) of sweets and sugar-sweetened soft drinks: Cardiovascular Risk in Young Finns Study

\begin{tabular}{|c|c|c|c|c|c|c|}
\hline & \multicolumn{3}{|c|}{ Males } & \multicolumn{3}{|c|}{ Females } \\
\hline & $n$ & OR & $95 \% \mathrm{Cl}$ & $n$ & OR & $95 \% \mathrm{Cl}$ \\
\hline \multicolumn{7}{|l|}{ Sweets } \\
\hline \multicolumn{7}{|l|}{ Model 1} \\
\hline Increase & 487 & 0.97 & $0 \cdot 70,1 \cdot 34$ & 364 & 0.83 & $0 \cdot 60,1 \cdot 14$ \\
\hline Stable high & 124 & 0.94 & $0 \cdot 60,1 \cdot 48$ & 68 & 0.55 & $0.30,1 \cdot 00$ \\
\hline Stable low & 212 & $1 \cdot 00$ & ref & 365 & $1 \cdot 00$ & ref \\
\hline Decrease & 154 & $1 \cdot 08$ & $0 \cdot 73,1 \cdot 60$ & 381 & $1 \cdot 10$ & $0 \cdot 82,1 \cdot 47$ \\
\hline \multicolumn{7}{|l|}{ Model 2} \\
\hline Increase & 475 & 1.09 & $0.77,1.54$ & 361 & 0.87 & $0 \cdot 63,1 \cdot 22$ \\
\hline Stable high & 123 & 1.01 & $0.63,1.60$ & 68 & 0.62 & $0.34,1 \cdot 12$ \\
\hline Stable low & 211 & $1 \cdot 00$ & ref & 363 & $1 \cdot 00$ & \\
\hline Decrease & 153 & $1 \cdot 14$ & $0 \cdot 76,1 \cdot 71$ & 378 & 1.05 & $0.77,1 \cdot 43$ \\
\hline \multicolumn{7}{|l|}{ Model 3} \\
\hline Increase & 466 & $1 \cdot 02$ & $0 \cdot 71,1 \cdot 46$ & 355 & $0 \cdot 87$ & $0 \cdot 62,1 \cdot 22$ \\
\hline Stable high & 121 & 1.04 & $0.65,1.68$ & 66 & 0.64 & $0.35,1.16$ \\
\hline Stable low & 203 & $1 \cdot 00$ & ref & 352 & $1 \cdot 00$ & ref \\
\hline Decrease & 149 & $1 \cdot 12$ & $0 \cdot 73,1 \cdot 71$ & 371 & 1.05 & $0.77,1.44$ \\
\hline \multicolumn{7}{|l|}{ Soft drinks } \\
\hline \multicolumn{7}{|l|}{ Model 1} \\
\hline Increase & 351 & 0.99 & $0 \cdot 70,1 \cdot 40$ & 387 & 1.90 & $1 \cdot 51,2 \cdot 56$ \\
\hline Stable high & 151 & $1 \cdot 07$ & $0 \cdot 70,1 \cdot 63$ & 76 & $1 \cdot 50$ & $0.90,2.51$ \\
\hline Stable low & 209 & $1 \cdot 00$ & ref & 385 & $1 \cdot 00$ & ref \\
\hline Decrease & 266 & 0.97 & $0 \cdot 67,1 \cdot 40$ & 330 & 1.09 & $0.79,1 \cdot 50$ \\
\hline \multicolumn{7}{|l|}{ Model 2} \\
\hline Increase & 343 & $1 \cdot 02$ & $0 \cdot 71,1 \cdot 47$ & 385 & 1.92 & $1 \cdot 40,2 \cdot 62$ \\
\hline Stable high & 146 & 1.06 & $0.68,1.64$ & 76 & $1 \cdot 62$ & $0 \cdot 85,2 \cdot 75$ \\
\hline Stable low & 206 & $1 \cdot 00$ & ref & 382 & $1 \cdot 00$ & ref \\
\hline Decrease & 264 & 0.94 & $0 \cdot 64,1 \cdot 38$ & 327 & $1 \cdot 07$ & $0.77,1.50$ \\
\hline \multicolumn{7}{|l|}{ Model 3} \\
\hline Increase & 327 & $1 \cdot 07$ & $0 \cdot 74,1 \cdot 57$ & 379 & $1 \cdot 90$ & $1 \cdot 38,2 \cdot 61$ \\
\hline Stable high & 146 & $1 \cdot 13$ & $0 \cdot 71,1 \cdot 78$ & 75 & $1 \cdot 71$ & $0.99,2.93$ \\
\hline Stable low & 199 & $1 \cdot 00$ & ref & 373 & $1 \cdot 00$ & ref \\
\hline Decrease & 357 & 0.93 & $0 \cdot 62,1 \cdot 39$ & 317 & $1 \cdot 11$ & $0.79,1.56$ \\
\hline
\end{tabular}

ref, referent category.

Model 1: adjusted for age in childhood.

Model 2: adjusted for age and overweight status in childhood and education in adulthood.

Model 3: adjusted for age and overweight status in childhood and education, smoking and physical activity in adulthood.

with logistic regression analysis (Table 4). In women, an increase $(\mathrm{OR}=1 \cdot 90,95 \% \mathrm{CI} 1 \cdot 38,2 \cdot 61)$ in the consumption of sugar-sweetened soft drinks from childhood to adulthood was associated with being overweight in adulthood. In men, no association was found. Furthermore, after adjusting for age and overweight status in childhood and education, smoking and physical activity in adulthood, the change in consumption of sweets was not associated with being overweight in adulthood. In addition, we compared the risk of being overweight in 
adulthood between combined frequency categories (daily and nearly daily; $1-3$ times a week and less frequently) of sweets and sugar-sweetened soft drinks both in childhood and adulthood (data not shown). No association was found between overweight in adulthood and the frequency of consumption of sweets and sugar-sweetened soft drinks in childhood. In adult women, sugarsweetened soft drinks frequency categories from daily to 2-3 times a week were associated with being overweight in adulthood (daily and nearly daily: $\mathrm{OR}=2 \cdot 02,95 \% \mathrm{CI}$ $1 \cdot 27,3 \cdot 23 ; 1-3$ times a week: $\mathrm{OR}=2 \cdot 00,95 \%$ CI $1 \cdot 51$, $2 \cdot 63$ ) and less frequently: $\mathrm{OR}=1 \cdot 00$. In adult men, no association was found.

\section{Discussion}

To our knowledge, the present study is one of the first to investigate the association between childhood consumption of sweets and sugar-sweetened soft drinks and adulthood overweight. Measured as the frequency of consumption, no association was found. However, adulthood BMI and overweight were directly associated with an increase in the consumption of sugar-sweetened soft drinks from childhood and adulthood in women.

Some previous longitudinal studies have observed a direct association $^{(10,12,13)}$ between overweight and sugarsweetened soft drinks consumption. In studies from the USA, the consumption of sugar-sweetened soft drinks was directly associated with obesity and weight gain in a 19-month follow-up among children aged 11 and 12 years $^{(12)}$, in a 2-year follow-up among children aged 9-14 years ${ }^{(10)}$ and in an 8-year follow-up among adult females ${ }^{(13)}$. The results from a Norwegian study with a follow-up almost as long as in our study are consistent with our findings, observing no association between sugarsweetened soft drinks consumption and overweight among adolescents followed from 15 to 33 years of age ${ }^{(11)}$. In our study the association between the change in consumption frequency and overweight was stronger than the association between childhood consumption frequency and overweight. Effectively, the analysis of overweight and the change in frequency can be considered a cross-sectional one, which may at least partly explain the difference in the strength of the associations. However, as the increased risk was observed specifically among those with an increase in the consumption frequency, regardless of the original level, these results indicate the usefulness of the longterm design over cross-sectional.

\section{Dietary habits}

One explanation for our result is that although body weight is a consequence of health behaviour over time, dietary habits seem to affect body weight and BMI fairly immediately, and therefore a 21 -year period may be too long a time to detect any association between dietary habits and body weight. Studies investigating whether dietary habits change or remain similar from childhood to adulthood have given inconclusive results, possibly due to cultural and methodological differences ${ }^{(18,21-24)}$. Childhood diet has been shown to be a significant determinant of diet in adulthood in the present study cohort ${ }^{(18,25)}$. Thus, it is reasonable to expect that dietary habits in childhood and adolescence may play a role in adulthood obesity. Other foods, dietary variables or habits may influence body weight or the consumption frequency of sweets and sugarsweetened soft drinks. However, there is evidence that the association of sugar-sweetened beverages and weight is independent of the influence of other foods ${ }^{(26)}$ and therefore we did not control for other dietary variables or dietary habits in the current study.

\section{Portion size}

Portion sizes of many foods, such as sweets, soft drinks, fast food and bread, have increased in the last few decades in both the USA ${ }^{(27)}$ and Europe ${ }^{(28)}$. Portion sizes of sweets and soft drinks have also been on the rise in Finland (S Heiskanen, Director, Finnish Food and Drinks Industries Federation, personal communication, April 2006). For soft drinks, the most popular portion size sold is 1.5 litres, replacing the previous portion size of 1 litre. For sweets, not only bigger package sizes but also increased sales of separately sold sweets that are consumer-selected have increased the consumed portions of sweets. The increase in the prevalence of obesity has occurred in parallel with increased portion sizes, which suggests that large portion sizes may play a role in the obesity epidemic ${ }^{(29)}$. This suggestion has been presented and considered with caution since it is difficult to establish a causal relationship between portion sizes and obesity ${ }^{(30)}$. Nevertheless, previous data indicate that portion size does indeed influence energy intake ${ }^{(30)}$. In our study, the consumption of sweets and sugar-sweetened soft drinks was assessed with a short FFQ without any information on portion sizes. It can be assumed, however, that at baseline the portion sizes of sweets and soft drinks were on average smaller than today, and therefore, with present portion sizes and consumption, the results of our study might be different.

\section{Liquid v. solid carbobydrate}

We found in women direct associations between increase in the consumption frequency of sugar-sweetened soft drinks and BMI and overweight in adulthood. The consumption or the change in consumption of sweets, by contrast, was not associated with BMI or being overweight. One explanation for this result could be related to the type of carbohydrates in these foods. Evidence that liquids have less impact on satiety than solid foods is inconclusive $^{(31)}$ when only the form (liquid $v$. solid) is investigated, regardless of the nutrient or energy content. When investigating the type of carbohydrate, the effect on energy compensation or satiety seems to be different ${ }^{(32)}$. 
In a 4-week study, solid carbohydrates (as jellybean sweets) were compensated in total energy intake, whereas liquid carbohydrates (as soft drinks) were not compensated but rather added to the total energy intake, resulting in a positive energy balance and a significant increase in BMI. DiMeglio and Mattes ${ }^{(32)}$ suggested that the act of masticating the solid carbohydrate may provide an internal satiety signal not triggered by swallowing a liquid carbohydrate.

\section{Gender differences}

In our study, the increase in sugar-sweetened soft drink consumption was associated with overweight only in women, not in men. This may be due to gender differences in consumption. In our study, boys and men consumed sugar-sweetened soft drinks more often than girls and women. Consumption of sugar-sweetened soft drinks could be a better marker of unhealthy eating behaviour in women than in men. It is possible that women who frequently consume sugar-sweetened soft drinks more often have unhealthy eating behaviour than women who infrequently consume sugar-sweetened soft drinks.

\section{Strengths and limitations}

Data for the present study were derived from the Cardiovascular Risk in Young Finns Study, where the same participants were followed for 21 years. The main strength of this study is the longitudinal study design, which allows us to investigate the diet and BMI of the same participants as children and as adults. Instead of self-reports, body height and weight were measured, and thus no self-report bias in BMI or in the prevalence of overweight and obesity exists. In the regression models we controlled for physical activity level as suggested in reviews by Malik et $a l^{(33)}$ and Bachman et al. ${ }^{(9)}$.

Since the present study was observational, we cannot establish causal relationships from the results. The method of assessment of sweets and sugar-sweetened soft drinks consumption describes the frequency of consumption, and not the absolute amounts consumed. Furthermore, we cannot exclude under-reporting, which is a common error in self-reports of food intake ${ }^{(34-36)}$. Foods considered unhealthy or fattening ${ }^{(37,38)}$ or high in carbohydrates $^{(39)}$ are under-reported more frequently. BMI also affects self-reports of food intake, with people with high adiposity tending to under-report more often $^{(34-36,40)}$. Under-reporting may partly explain why we did not find any association between sweets and soft drinks consumption and overweight. Since we did not assess the amount or the portion sizes of sweets and soft drinks consumed, it is possible that the overweight participants actually consumed sweets and soft drinks less often than their normal-weight peers, but ate or drank larger portions, thus consuming comparable or even greater amounts of sweets or soft drinks. Furthermore, a possible confounder could be artificially sweetened soft drinks since these drinks might have been preferred by participants who tried to lose weight. Artificially sweetened beverages were not included in the frequency questionnaire of our study.

\section{Conclusions}

In conclusion, we found in women direct associations between both adulthood BMI and overweight and increasing sugar-sweetened soft drinks consumption from childhood or adolescence. Although our study did not find any association between overweight and childhood consumption of sweets and sugar-sweetened soft drinks, we emphasize that sweets and sugar-sweetened soft drinks are important when considering weight management or body weight. Obesity is not merely a consequence of eating too much of just one or two foods (e.g. sweets or soft drinks), but rather an overall imbalance of the diet and other lifestyle factors. Body weight is an outcome of balance between energy intake and energy expenditure, and especially if sugar-sweetened soft drinks are not compensated in the total energy intake, the balance can become positive, resulting in weight gain. Furthermore, consumption of sweets and sugar-sweetened soft drinks may be a marker of unhealthy lifestyle or unrecognized factors that affect body weight. There is evidence, supported by our results as well, that sugar-sweetened soft drinks are associated with weight gain and obesity. With parallel increases in the prevalence of obesity and the consumption of sweets and sugar-sweetened soft drinks, more research is needed to clarify the association between obesity and diet in general, including the consumption of sweets and sugarsweetened soft drinks. As obesity is such a widespread problem among young adults - in our study, $52 \%$ of men and $36 \%$ of women were at least overweight - identification of underlying causes of obesity in young adults is essential.

\section{Acknowledgements}

Sources of funding: This study was financially supported by the Academy of Finland (grant no. 77841 and 210283), the Finnish Cultural Foundation, the Juho Vainio Foundation and the Yrjö Jahnsson Foundation. Conflict of interest declaration: None declared. Authorship responsibilities: K.N., V.M., S.M., M.L.-K. and L.R. designed the study and the statistical analyses and models. K.N. and V.M. drafted the initial manuscript. K.N. drafted the final manuscript. V.M. ran the statistical analyses. L.R. is responsible for the nutritional field studies of the project. O.T.R. and J.V. are responsible for the project. All authors contributed to the interpretation of the data, revised the manuscript critically and approved the final version of the manuscript. 


\section{References}

1. Kautiainen S, Rimpelä A, Vikat A \& Virtanen SM (2002) Secular trends in overweight and obesity among Finnish adolescents in 1977-1999. Int J Obes Relat Metab Disord 26, 544-552.

2. International Obesity Taskforce, European Association for the Study of Obesity (2002) Obesity in Europe. Case for Action. London: IOTF.

3. Popkin BM \& Nielsen SJ (2003) The sweetening of the world's diet. Obes Res 11, 1325-1332.

4. Finnish Food and Drink Industries' Federation (2005) Domestic Sales of Finnish Food Products. http://www. etl.fi/english/stat/pdf/kotimaa2004_ENG.pdf (accessed March 2006).

5. Federation of the Brewing and Soft Drinks Industry (2005) Consumption of beverages, litres per capita. http:// www.panimoliitto.fi/panimoliitto/en/statistics/consumption of_beverages_1980_2004.pdf (accessed March 2006).

6. Federation of the Brewing and Soft Drinks Industry (2005) Domestic sales of the Brewing and Soft Drinks Industry. http:// www.panimoliitto.fi/panimoliitto/en/statistics/domestic_sales_ 1980 2004.pdf (accessed March 2006).

7. Phillips SM, Bandini LG, Naumova EN, Cyr H, Colclough S, Dietz WH \& Must A (2004) Energy-dense snack food intake in adolescence: longitudinal relationship to weight and fatness. Obes Res 12, 461-472.

8. Janssen I, Katzmarzyk PT, Boyce WF, Vereecken C, Mulvihill C, Roberts C, Currie C \& Pickett W (2005) Comparison of overweight and obesity prevalence in school-aged youth from 34 countries and their relationships with physical activity and dietary patterns. Obes Rev 6, 123-132

9. Bachman CM, Baranowski T \& Nicklas TA (2006) Is there an association between sweetened beverages and adiposity? Nutr Rev 64, 153-174.

10. Berkey CS, Rockett HR, Field AE, Gillman MW \& Colditz GA (2004) Sugar-added beverages and adolescent weight change. Obes Res 12, 778-788.

11. Kvaavik E, Andersen LF \& Klepp KI (2005) The stability of soft drinks intake from adolescence to adult age and the association between long-term consumption of soft drinks and lifestyle factors and body weight. Public Health Nutr 8 , 149-157.

12. Ludwig DS, Peterson KE \& Gortmaker SL (2001) Relation between consumption of sugar-sweetened drinks and childhood obesity: a prospective, observational analysis. Lancet 357, 505-508.

13. Schulze MB, Manson JE, Ludwig DS, Colditz GA, Stampfer MJ, Willett WC \& Hu FB (2004) Sugar-sweetened beverages, weight gain, and incidence of type 2 diabetes in young and middle-aged women. JAMA 292, 927-934.

14. Juonala M, Viikari JS, Hutri-Kähönen N, Pietikäinen M, Jokinen E, Taittonen L, Marniemi J, Rönnemaa T \& Raitakari OT (2004) The 21-year follow-up of the Cardiovascular Risk in Young Finns Study: risk factor levels, secular trends and east-west difference. J Intern Med 255, 457-468.

15. Åkerblom HK, Viikari J, Raitakari OT \& Uhari M (1999) Cardiovascular Risk in Young Finns Study: general outline and recent developments. Ann Med 31, Suppl. 1, 45-54.

16. Raitakari OT, Juonala M, Kähönen M et al. (2003) Cardiovascular risk factors in childhood and carotid artery intima-media thickness in adulthood: the Cardiovascular Risk in Young Finns Study. JAMA 290, 2277-2283.

17. Juonala M (2005) Cardiovascular risk factors and their associations with markers of subclinical atherosclerosis in young adults. The Cardiovascular Risk in Young Finns Study. Dissertation, University of Turku.

18. Mikkilä V, Räsänen L, Raitakari OT, Pietinen P \& Viikari J (2005) Consistent dietary patterns identified from childhood to adulthood: the cardiovascular risk in Young Finns Study. Br J Nutr 93, 923-931.

19. World Health Organization (2000) Obesity, Preventing and Managing the Global Epidemic. Report of the WHO Consultation on Obesity. Geneva: WHO.

20. Cole TJ, Bellizzi MC, Flegal KM \& Dietz WH (2000) Establishing a standard definition for child overweight and obesity worldwide: international survey. BMJ 320, 1240-1243.

21. Bertheke Post G, de Vente W, Kemper HC \& Twisk JW (2001) Longitudinal trends in and tracking of energy and nutrient intake over 20 years in a Dutch cohort of men and women between 13 and 33 years of age: The Amsterdam Growth and Health Longitudinal Study. Br J Nutr 85, 375-385.

22. Birch LL (1999) Development of food preferences. Annu Rev Nutr 19, 41-62.

23. Boreham C, Robson PJ, Gallagher AM, Cran GW, Savage JM \& Murray LJ (2004) Tracking of physical activity, fitness, body composition and diet from adolescence to young adulthood: The Young Hearts Project, Northern Ireland. Int J Behav Nutr Phys Act 1, 14.

24. Kelder SH, Perry CL, Klepp KI \& Lytle LL (1994) Longitudinal tracking of adolescent smoking, physical activity, and food choice behaviors. Am J Public Health 84, $1121-1126$.

25. Mikkilä V, Räsänen L, Raitakari OT, Pietinen P \& Viikari J (2004) Longitudinal changes in diet from childhood into adulthood with respect to risk of cardiovascular diseases: The Cardiovascular Risk in Young Finns Study. Eur J Clin Nutr 58, 1038-1045.

26. Bes-Rastrollo M, Sanchez-Villegas A, Gomez-Gracia E, Martinez JA, Pajares RM \& Martinez-Gonzalez MA (2006) Predictors of weight gain in a Mediterranean cohort: the Seguimiento Universidad de Navarra Study 1. Am J Clin Nutr 83, 362-370.

27. Young LR \& Nestle M (2002) The contribution of expanding portion sizes to the US obesity epidemic. Am J Public Health 92, 246-249.

28. Matthiessen J, Fagt S, Biltoft-Jensen A, Beck AM \& Ovesen L (2003) Size makes a difference. Public Health Nutr 6, 65-72.

29. Ledikwe JH, Ello-Martin JA \& Rolls BJ (2005) Portion sizes and the obesity epidemic. J Nutr 135, 905-909.

30. Ello-Martin JA, Ledikwe JH \& Rolls BJ (2005) The influence of food portion size and energy density on energy intake: implications for weight management. Am J Clin Nutr 82, 1 Suppl., 236S-241S.

31. Almiron-Roig E, Chen Y \& Drewnowski A (2003) Liquid calories and the failure of satiety: how good is the evidence? Obes Rev 4, 201-212.

32. DiMeglio DP \& Mattes RD (2000) Liquid versus solid carbohydrate: effects on food intake and body weight. Int J Obes Relat Metab Disord 24, 794-800.

33. Malik VS, Schulze MB \& Hu FB (2006) Intake of sugarsweetened beverages and weight gain: a systematic review. Am J Clin Nutr 84, 274-288.

34. Hill RJ \& Davies PS (2001) The validity of self-reported energy intake as determined using the doubly labelled water technique. Br J Nutr 85, 415-430.

35. Hirvonen T, Männistö S, Roos E \& Pietinen P (1997) Increasing prevalence of underreporting does not necessarily distort dietary surveys. Eur J Clin Nutr 51, 297-301.

36. Johansson G, Wikman A, Ahren AM, Hallmans G \& Johansson I (2004) Underreporting of energy intake in repeated 24-hour recalls related to gender, age, weight status, day of interview, educational level, reported food intake, smoking habits and area of living. Public Health Nutr 4, 919-927.

37. Lafay L, Mennen L, Basdevant A, Charles MA, Borys JM, Eschwege E \& Romon M (2000) Does energy intake 
underreporting involve all kinds of food or only specific food items? Results from the Fleurbaix Laventie Ville Sante (FLVS) study. Int J Obes Relat Metab Disord 24, 1500-1506.

38. Scagliusi FB, Polacow VO, Artioli GG, Benatti FB \& Lancha $\mathrm{AH} \mathrm{Jr}$ (2003) Selective underreporting of energy intake in women: magnitude, determinants, and effect of training. J Am Diet Assoc 103, 1306-1313.
39. Poppitt SD, Swann D, Black AE \& Prentice AM (1998) Assessment of selective under-reporting of food intake by both obese and non-obese women in a metabolic facility. Int J Obes Relat Metab Disord 22, 303-311.

40. Bedard D, Shatenstein B \& Nadon S (2004) Underreporting of energy intake from a self-administered food-frequency questionnaire completed by adults in Montreal. Public Health Nutr 7, 675-681. 